\title{
Original article Prevalence of Malocclusion Among School Children in Bangalore, India
}

\author{
${ }^{1}$ Usha Mohan Das, ${ }^{2}$ Venkatsubramanian, ${ }^{3}$ Divya Reddy \\ ${ }^{1}$ President, Professor and Head, Department of Pedodontics and Preventive Dentistry, VS Dental College and Hospital, Bangalore, \\ Karnataka, India \\ ${ }^{2}$ Senior Lecturer, Department of Pedodontics and Preventive Dentistry, VS Dental College and Hospital, Bangalore, Karnataka, India \\ ${ }^{3}$ Postgraduate, Department of Pedodontics and Preventive Dentistry, VS Dental College and Hospital, Bangalore, Karnataka, India \\ Correspondence: Dr Usha Mohan Das \\ President, Indian Society of Pedodontics and Preventive Dentistry, VS Dental College and Hospital, KR Road VV Puram \\ Bangalore, Karnataka, India \\ Phone No: 0091(80)-41692711, Fax: 0091(80)-22426705, e-mail:ushymohandas@gmail.com
}

\begin{abstract}
The objective of this study was to determine the prevalence of malocclusion among school children of Bangalore city, India during their mixed dentition period. The sample consisted of 745 children (388 males and 357 females) in the age group of 8-12 years randomly selected from twelve different schools in Bangalore city. The subjects were randomly selected, and none had received previous orthodontic treatment. Occlusal anteroposterior relationships were assessed based on the Angle classification. Also various malocclusion features associated with class I malocclusion according to Dewey's modification of Angle's classification were assessed. The results showed that about $71 \%$ of the subjects had malocclusion. Class I malocclusion constituted the major proportion of malocclusion which was found in $62 \%$ of the studied population. No significant difference was found between boys and girls neither in the overall prevalence of malocclusion nor in various forms of malocclusion. Crowded incisors was found to be most common finding in subjects with class I malocclusion. A number of studies have been conducted to determine the prevalence of malocclusion among Indian children and it has been reported that the results range from a value as low as $19.6 \%$ (Miglani DC, Chennai 1961) to as high as $90 \%$ (Sidhu SS, Delhi). This varied range emphasizes the need to standardize criteria for assessing malocclusion.
\end{abstract}

Keywords: Prevalence, Malocclusion, India.

\section{INTRODUCTION}

Well aligned teeth not only contribute to the health of the oral cavity and stomatognathic system, but also influence the personality of the individual. Malocclusion compromises the health of oral tissues and also can lead to psychological and social problems.

A systematic and well-organized dental care program for any target population in a community requires some basic information, such as the prevalence of the condition.

In more developed parts of the world, where the specialties of Orthodontics and Pedodontics have been established, adequate basic information is available $\mathrm{e}^{1-8}$ on the prevalence of this condition. In developing nations, such information still lack. ${ }^{9}$

With increasing interest in the early detection and treatment of malocclusion and a corresponding emphasis on preventive procedures, it would be beneficial to collect more information on patients at younger age levels.

Therefore, the aim of this study is to estimate the prevalence of malocclusion in school children of Bangalore city, India during their mixed dentition period so as to take preventive measures to recognize and minimize the potential irregularities in the developing dentofacial complex.

\section{MATERIALS AND METHODS}

The sample consisted of 745 children (388 males and 357 females) in the age group of 8-12 years randomly selected from twelve different schools in Bangalore city. None of the subjects had previous orthodontic treatment, and all had their first permanent molars.

All the students were examined by a single operator after obtaining the informed consent from the subjects and their 
parents. Approval to conduct the study was also received from the appropriate school authority.

The students were examined at their respective schools, using sterile mouth mirror and flash light.

All occlusal relationships were evaluated at a centric occlusion position, which was achieved by asking the subject to swallow and then to bite on his or her teeth together. The occlusion was then classified into normal occlusion or malocclusion using the first permanent molars as described by Angle. The cheeks were fully retracted to obtain a direct lateral view of the dentition in occlusion on each side.

Children with class I molar relationship, minimal overbite and overjet, proper alignment, and minimal crowding were classified as normal.

In subjects with class I malocclusion, class I molar relation existed with one or more of these characteristics: crowded incisors or labial canines, or both (Dewey type I), protruded maxillary incisors (Dewey type II), anterior end to end occlusion or anterior cross bite or both (Dewey type III), unilateral or bilateral posterior cross bite (Dewey type IV), mesial drift of molars (Dewey type V), anterior or posterior open bite, deep anterior overbite. The prevalence of these features were assessed in subjects showing Class I malocclusion.

The collected data were tabulated and analyzed statistically.

\section{RESULTS}

Table 1 shows the occlusal classifications of the subjects. Normal occlusions were found in $29 \%$ of subjects, and $71 \%$ had malocclusions. Figure 1 shows the distribution of various types of class I malocclusion according to Dewey's modification. Table 2 shows the gender distribution of

TABLE 1: Occlusal classifications

\begin{tabular}{lrc}
\hline Occlusal classification & $N$ & $\%$ \\
\hline Normal occlusion & 219 & 29.4 \\
Class I & 459 & 61.6 \\
Class II division I & 51 & 6.8 \\
Class II division II & 12 & 1.6 \\
Class III & 4 & 0.6 \\
\hline Total & $\mathbf{7 4 5}$ & $\mathbf{1 0 0}$ \\
\hline
\end{tabular}

TABLE 2: Gender distribution of occlusal variations

\begin{tabular}{lcc}
\hline Occlusion & Male $(n)$ & Female $(n)$ \\
\hline Normal occlusion & 102 & 117 \\
Class I & 238 & 221 \\
Class II division I & 33 & 18 \\
Class II division II & 6 & 6 \\
Class III & 4 & 0 \\
\hline Total & $\mathbf{3 8 3}$ & $\mathbf{3 6 2}$ \\
\hline
\end{tabular}

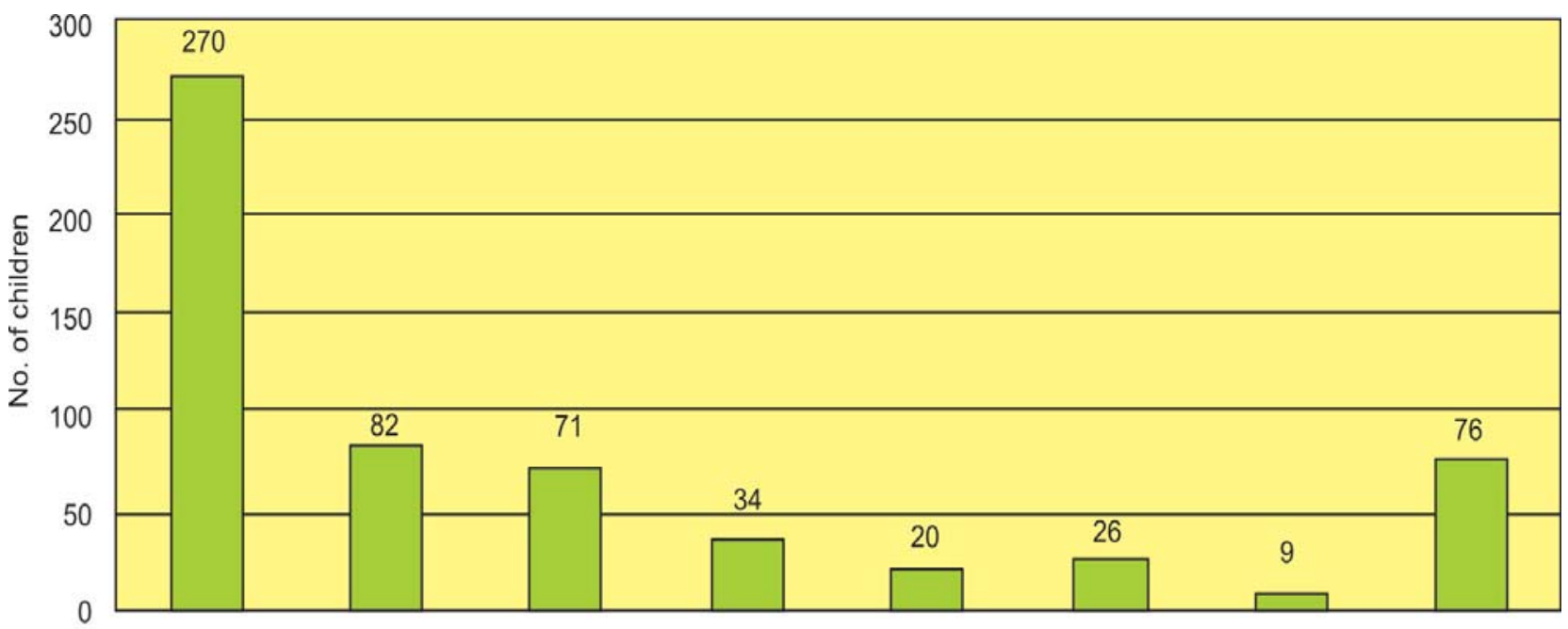

Fig. 1: Distribution of types of class I malocclusion according to Dewey's modification 
normal occlusion along with various forms of malocclusions. No statistically significant relationship was found for any gender variation as tested by chi-square test by taking $P$ values of less than 0.05 as statistically significant.

\section{DISCUSSION}

The results showed that $71 \%$ of the school children surveyed had malocclusion. This is similar to the findings of Prasad A Rajendra and Savadi $S^{10}$ who conducted an epidemiological study of malocclusion in the age group of 5-15 years in Bangalore city in 1971, reported a high incidence of malocclusion of $85.7 \%$ with $51.5 \%$ class I, $4 \%$ class II, $0.9 \%$ class III.

Findings of this present study are in disagreement with Nagaraja Rao $(1980)^{10}$ who found only $28.8 \%$ prevalence of malocclusion in school children of Udipi, Karnataka.

Class I malocclusion constituted the major proportion of malocclusion which was found in $62 \%$ of the studied population which is in agreement with the other studies.

No significant difference was found between boys and girls neither in the overall prevalence of malocclusion nor in various forms of malocclusion.

The present study evaluated various malocclusion features associated with class I malocclusion according to Dewey's modification of Angle's classification.

Crowded incisors was found to be most common finding in subjects with class I malocclusion followed by protruded maxillary incisors, anterior deep overbite, anterior cross bite, posterior cross bite and mesial drift of molars in descending order.

\section{CONCLUSION}

The following conclusions are drawn from the present study:

a. Prevalence of malocclusion was found to $71 \%$

b. Class I malocclusion is the most prevalent occlusal pattern.

c. Crowded incisors were the most common feature associated with class I malocclusion. d. No statistically significant sex differences were found among the subjects.

A number of studies have been conducted to determine the prevalence of malocclusion among Indian children and it has been reported that the results range from a value as low as $19.6 \%$ (Miglani DC, Chennai 1961) to as high as 90\% (Sidhu SS, Delhi). This varied range emphasizes the need to standardize criteria for assessing malocclusion.

\section{ACKNOWLEDGMENTS}

I thank the Faculty of the Department of Pedodontics and Preventive Dentistry, VS Dental College and Hospital, Bangalore, the school authorities and the parents and children for their cooperation in conducting this study.

\section{REFERENCES}

1. Sclare AR. Othodontics and the school child: a survey of 680 children. Br Dent J 1945;79:278-80.

2. Bjork A. The face in profile: an anthropological X-ray investigation on Swedish children and conscripts. Sverisk TandiTidsk 1947;40(suppl 5B):180.

3. Gardiner JH. A survey of malocclusion and some aetiological factors in 1000 Sheffield school children. Dent Practit 1957;6: 187-198.

4. Goose DH, Thompson DG, Winter FC. Malocclusion in school children of West Midlands. Br Dent J 1957;102:174-178.

5. Altemus L. The frequency of the incidence of malocclusion in American Negro children aged 12-16. Angle Orthod 1959 Oct; 29(4):189-200.

6. Massler M, Frankel J. Prevalence of malocclusion in children aged 14 to 18 years. Am J Orthod 1951 Oct;37(10):751-768.

7. Foster TD, Day AJW. A survey of malocclusion and the need for orthodontic treatment in a Shropshire school population. $\mathrm{Br}$ J Othod 1974 Apr;1(3):73-78.

8. Roberts EE, Goose DH. Malocclusion in a North Wales population. Br Dent J 1979 Jan;146(1):17-20.

9. Onyeaso CO. Prevalence of malocclusion among adolescents in Ibadan, Nigeria. Am J Orthod Dentofacial Orthop 2004 Nov; 126(5):604-607.

10. Peter, S. Essentials of preventive community dentistry. 3rd ed. New Delhi: Arya Publishing House; 2006. Chapter 36, Epidemiology, etiology and classification of malocclusion. 